\title{
A New Model of Obstetrical Pessary - Prevention and Treatment of Cervical Insuf- ficiency and Habitual Abortion
}

\author{
Schneiderman $\mathrm{M}^{* 1}$, Kalinina $\mathrm{E}^{1}$, Yarotskaya $\mathrm{E}^{1}$, Pavlovich $\mathrm{S}^{1}$, Zinenko $\mathrm{D}^{2}$, Gorshkov $\mathrm{A}^{2}$ and Sukhikh $\mathrm{G}^{1}$ \\ ${ }^{1}$ Research Center for Obstetrics, Gynecology and Perinatology, Ministry of Health of Russia, Moscow \\ ${ }^{2}$ Join Stock Company "MedSil
}

${ }^{*}$ Corresponding author: Schneiderman M, Research Center for Obstetrics, Gynecology and Perinatology, Ministry of Health of Russia, Moscow, E-mail: innamike@lmi.net

Citation: Schneiderman M, Kalinina E, Yarotskaya E, Pavlovich S, Zinenko D, et al. (2016) A New Model of Obstetrical Pessary - Prevention and Treatment of Cervical Insufficiency and Habitual Abortion. J Gynecol Res 2(1): 106

Received Date: September 01, 2016 Accepted Date: November 15, 2016 Published Date: November 18, 2016

\begin{abstract}
This article presents a new model of obstetrical pessary for prevention and treatment of cervical insufficiency and habitual abortion.

In 2012 Research Center for Obstetrics, Gynecology and Perinatology (of the Ministry of Health of Russia) received an assignment from the Ministry of Health of Russia to develop a new medical device for correction and treatment of conditions associated with habitual abortion. In accordance with this task, a group of the Center`s researchers and obstetricians developed a new model of obstetrical pessary. In 2013 the Ethics Commission on biological and medical investigations of the Center authorized clinical use of this device.

Keywords: Obstetrical pessary; Cervical insufficiency; Habitual abortion; Cervical length; Preterm birth
\end{abstract}

\section{Introduction}

For many years the following obstetrical pessaries have been used in Russia: "Yunona” by the Simurg, Belarus, and "Dr. Arabin", manufactured in Germany [1,2].

Review of existing models of pessaries has identified a number of shortcomings in their design and adverse effects or complications during use. The most common of these are discomfort, pain, expulsion, vaginal irritation, bacterial vaginosis, actinomycosis and allergic reactions to latex inducing discontinuation. These adverse events are associated with inadequate form or material of a pessary. Excessive vaginal secretion and erosions are also the sequela of the inadequate quality of the material used, its density, susceptibility to microbial contamination and chemical degradation $[3,4]$. The main objective was therefore to design a new model of obstetrical pessary without the above-mentioned shortcomings.

\section{Methods}

A new model of obstetrical pessary designed by the authors and developed jointly by the Research Center for Obstetrics, Gynecology and Perinatology of the Ministry of Health of Russia and ZAO "MEDSIL" is made of high quality silicone of predefined flexibility and density providing optimal application of the pessary. Application of pessary is easy and painless.

A specific feature of the new model of obstetrical pessary by Dr. Shneiderman (Model 1/Figure 1) are four semi-circular symmetrically located notches on the outer surface of the ring (due to these the pessary adjoins the vaginal walls and is retained reliably in a predetermined position without displacement). Another useful feature is four symmetrical semicircular bulges on the inner surface of the ring, which compress the cervix from four sides, preventing its opening (Figure 1) [5].

An exclusive innovation of pessary (Model 2/Figure 2) are four vertical silicon "lobes" at the lower surface of pessaries preventing from a shift or turn to a wrong position.

Absolutely new and significant advantage of the new model is its antimicrobial coating (miramistin, chlorhexidine, silver), preventing development of bacterial vaginosis which may impede use of a pessary [6].

The mechanism of prevention of cervical dilatation is based on cervical compression provided by the internal bulges and partial transfer of intrauterine pressure to the anterior wall of the uterus. 


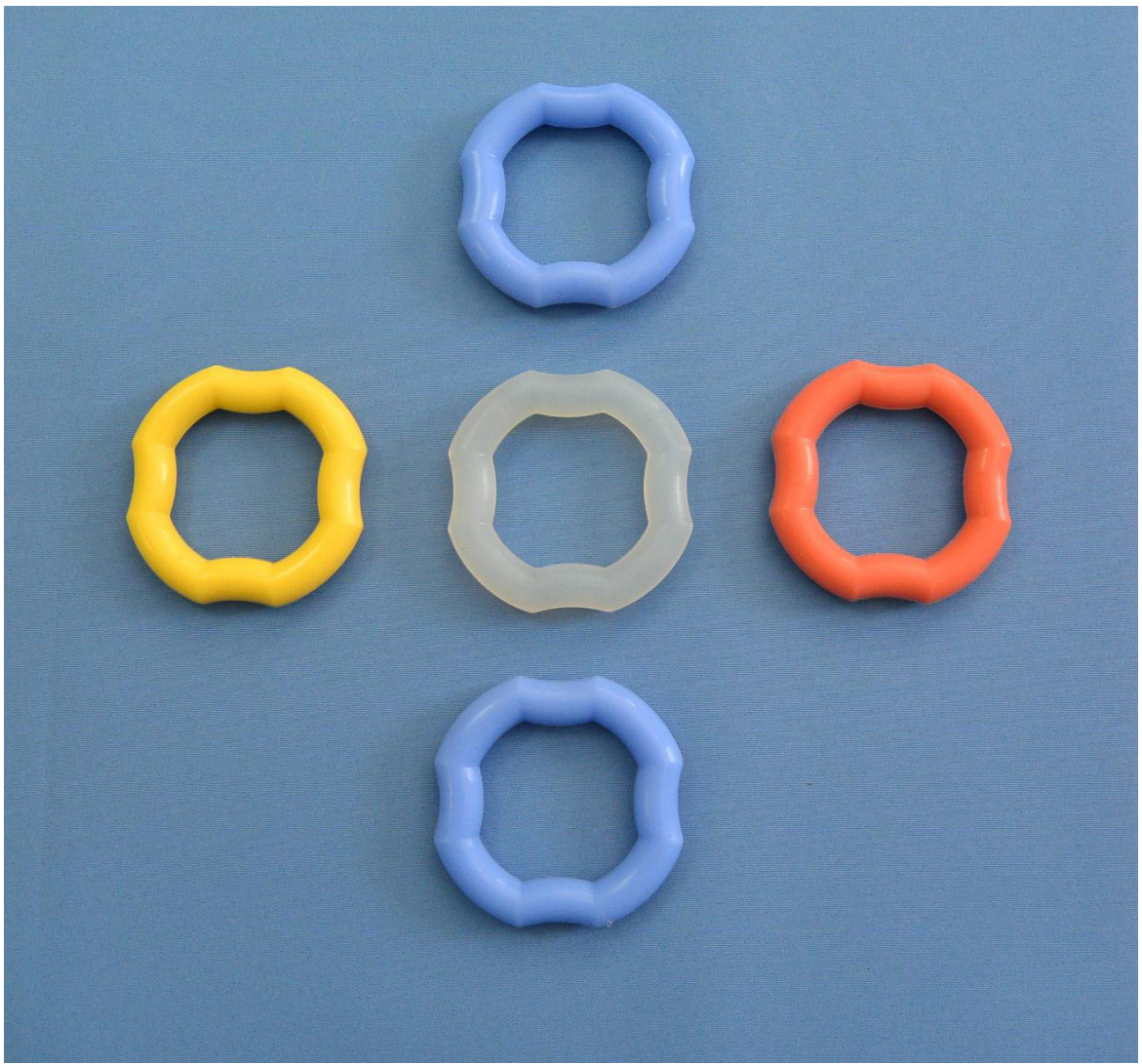

Figure 1: Obstetrical pessary by Dr. Shneiderman (Model 1: four symmetrical semicircular slots on the external surface of the ring, four bulges on the internal surface of the ring.).

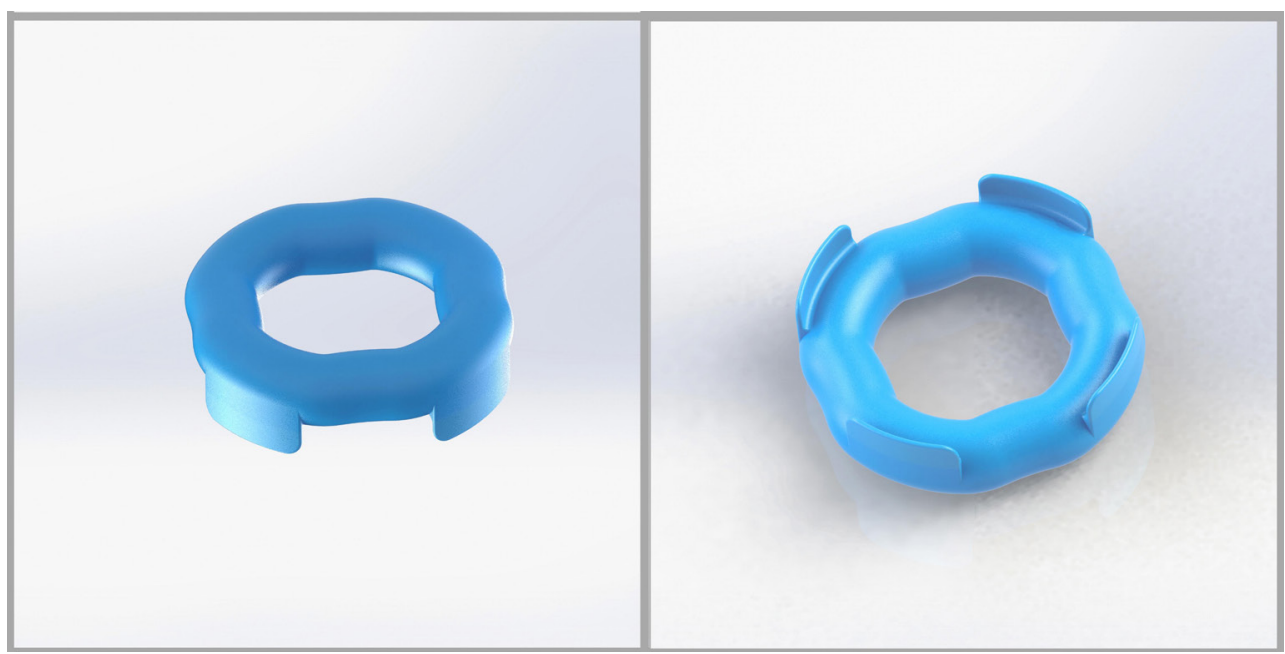

Figure 2: Obstetrical pessary by Dr. Shneiderman (Model 2).

The inner part of the pessary is made of silicone rubber with Shore hardness A-60 units, and the outer part - of silicone rubber with Shore hardness of A-10 units or of cellular rubber, containing 2-4 wt. of silver nanoparticles.

The outer layer of silicone rubber with hardness of A-10 units or of cellular rubber applies minimal pressure to adjacent tissues, allowing avoiding their irritation, pressure ulcers, erosion, and stretching. In the same time, the use for the inner rubber layer with a Shore hardness of A-60 units provides the necessary compression and limits axial and radial movement of the device [7].

A new modified model has several structural differences from existing devices and reliably prevents the opening of the cervix in pregnant women with cervical incompetence as well as stress urinary incontinence. Installation of pessary is possible in outpatient setting thus providing the economic feasibility of the treatment.

Installation of the pessary should be done by an obstetrician-gynecologist. The doctor holds the pessary (its 2 opposite outer cuts) with two fingers, compressing it in vertical position, and introduces it into vagina up to its vault. The pessary can be easily and painlessly removed from vagina (Figure 3). 
Then with the index finger the doctor ensures that the cervix comes to the central opening of the pessary, and the installation is accomplished.

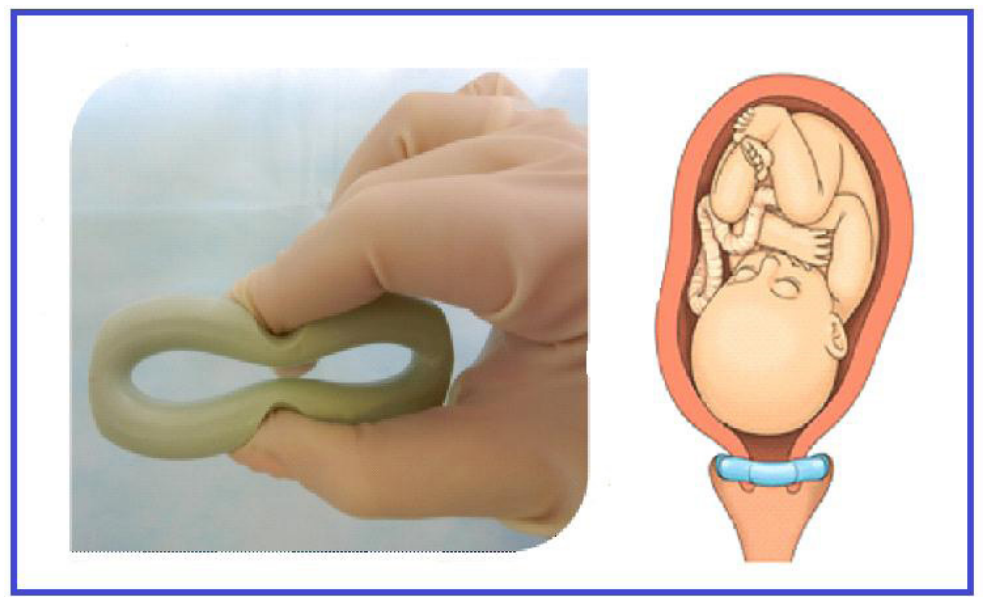

Figure 3: Installation of the pessary

The pessary is available in two sizes: for parous and nulliparous women. The appropriate choice cancels use of diaphragm in case if a pessary does not fit (Figure 4).

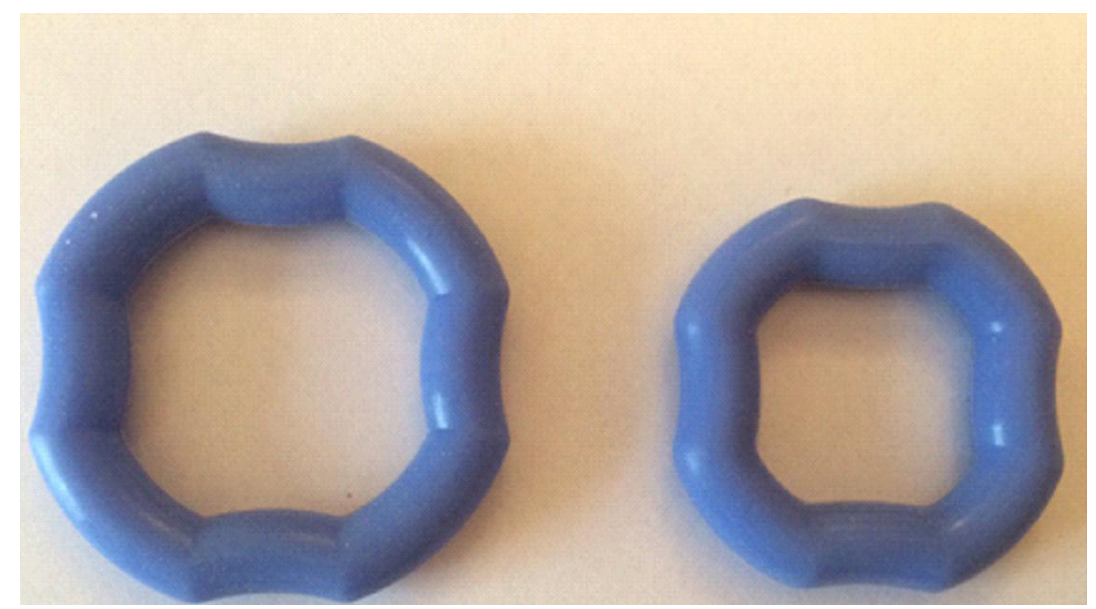

Figure 4: Pessaries for parous (left) and nulliparous (right) women

This study included 108 pregnant women aged 18 - 43 years (average $20.4 \pm 1.2$ years). All patients underwent clinical and laboratory evaluation and ultrasonic monitoring of the cervical internal os and cervical canal, defining the degree of severity of cervical insufficiency. Cervical incompetence was classified according to the following categories:

1. Congenital isthmic-cervical insufficiency (due to uterine malformations, genital infantilism).

2. Functional cervical insufficiency (due to endocrine dysfunction).

3. Organic isthmic-cervical insufficiency (following traumatic birth, manipulations or surgery on the cervix).

The optimal terms for use of obstetrical pessary are 17-37 weeks of gestation.

\section{Results}

The study of the new model of obstetrical pessary by doctor Schneiderman demonstrated its high reliability and efficiency. The patients' personal data and pregnancy outcomes after the treatment of isthmic-cervical insufficiency using pessary are presented in Table A.

The subjects of the study were 108 women diagnosed with isthmic-cervical insufficiency, followed for three years. The criteria for initiation of the preventive treatment of patients at high risk of preterm birth were the following: cervical length $\leq 25 \mathrm{~mm}$ measured by ultrasonography and dilatation of cervical internal os more than $0,8 \mathrm{~mm}$ at the 15 th -16 th week of gestation and every 2 weeks on wards.

After installation of the pessary 2 patients (1.16\%) reported the sensation of "fullness" in vagina, which resolved in one-two days. 34 women had the history of miscarriage in the 2 nd trimester, 34 women (31.4\%) were nulliparous, 8 women (7.3\%) had previous operations on the cervix. Cervical length in 32 women $(29.6 \%)$ was less than $2.5 \mathrm{~cm}$. The pessaries were installed within the period 
17.3 - 31.2 weeks of gestation. 99 women $(91.6 \%)$ delivered after the $34^{\text {th }}$ week of gestation, 9 women (8.3\%) delivered before the $34^{\text {th }}$ week. The outcomes of all deliveries were successful. There was not a single case of development of pressure sores of the vaginal wall or bleeding associated with trauma to the vaginal mucosa. There were no uterine contractions before or after installation of the pessary, therefore no tocolysis was necessary. Removal of the pessary at the $37^{\text {th }}-38^{\text {th }}$ weeks of gestation was painless and uneventful. The use of the new pessary allowed to maintain pregnancy in all 108 pregnant women to term [8,9]. The analysis of pregnancy duration after treatment with pessary is demonstrated in Table A.

\begin{tabular}{|c|c|}
\hline Age (average) & $20.4+1.2(\mathbf{1 8}-43)$ \\
\hline One miscarriage in the $2^{\text {nd }}$ trimester of pregnancy & $22(\mathbf{2 0 . 3} \%)$ \\
\hline Two miscarriages in the $2^{\text {nd }}$ trimester of pregnancy & $10(9.25 \%)$ \\
\hline Three miscarriages in the $2^{\text {nd }}$ trimester of pregnancy & $2(\mathbf{1 . 8 5} \%)$ \\
\hline Nulliparous & $34(31.4 \%)$ \\
\hline Preterm birth & $46(42.6 \%)$ \\
\hline Cervical surgery & $\mathbf{8}(7.3 \%)$ \\
\hline Average cervix $(\mathrm{cm})$ & $2.0(\mathbf{1 . 6}-\mathbf{2 . 5})$ \\
\hline
\end{tabular}

Table A: Medical history data of patients

The majority of patients using pessaries delivered at $39-40$ weeks though the pessaries were removed at $37^{\text {th }}-38^{\text {th }}$ weeks of gestation and gestation was prolonged by 8-12 days before labor. Urogenital infection associated with isthmic-cervical insufficiency was diagnosed in $10.4 \%$ of cases [10]. Bacterial vaginosis, candidiasis and opportunistic infections were mostly detected. Analysis of complications during pregnancy, delivery and postpartum period is shown in Table B.

\begin{tabular}{|c|c|}
\hline Terms of pregnancy at pessary installation (average, weeks) & $24.1(17.1-31.2)$ \\
\hline Discomfort after installation of the pessary (1-2 days) & $2(1.16 \%)$ \\
\hline Interval from removal of the pessary to delivery (days) & $10.0(8-12)$ \\
\hline Term of delivery (average, weeks) & $36.7(34-40.2)$ \\
\hline Delivery after the $34^{\text {th }}$ week of gestation & $99(91.6 \%)$ \\
\hline Delivery before the $34^{\text {th }}$ week of gestation & $9(8.3 \%)$ \\
\hline Duration of pregnancy prolongation (days) & $45(18.0-62.0)$ \\
\hline Cervical length $<2.5 \mathrm{~cm}$ & $32(29.6 \%)$ \\
\hline Cervical length $>2.5 \mathrm{~cm}$ & $76(70.3 \%)$ \\
\hline Dilatation of internal cervical os $(>0.8 \mathrm{~mm})$ & $64(59.2 \%)$ \\
\hline
\end{tabular}

Table B: Outcomes

Low incidence or absence of severe obstetrical complications such as intrauterine growth restriction and placental abruption. Chorioamnionitis was not detected.

\section{Discussion}

The article represents study results of the use of new models of obstetrical pessaries designed by Dr. Schneiderman in pregnant women with isthmic-cervical insufficiency and habitual abortion. Different aspects of the use of the new models of obstetrical pessaries have been investigated. The criteria for the treatment of patients at high risk of miscarriage or preterm birth were the following: cervical length $<25 \mathrm{~mm}$ and dilatation of internal cervical os more than $0.8 \mathrm{~mm}$. The use of the new pessaries enabled to prolong pregnancy by 45 (18-62) days.

The advantages of the new models of the obstetrical pessary are as follows:

1. Bulges on the internal surface of the ring preventing cervical dilatation in case of cervical insufficiency during pregnancy.

2. Stable fixation of the pessary in the vagina due to the external slots and lobes (preventing displacement or expulsion).

3. Reduced risk of lacerations of the vaginal mucosa due to minimal pressure to the vaginal wall.

4. Facilitated outflow of the vaginal discharge.

5. High comfort and easy installation.

6. Allergy free pessary.

7. Easy and painless removal of the pessary.

8. Elimination of symptoms of stress urinary incontinence.

Investigation of numerous cases evidences that the use of the new models of obstetrical pessaries provides support of pregnancy in patients with isthmic-cervical insufficiency.

Lack of comparative analysis of different models of pessaries is a drawback of this investigation; however again, the aim of the present study was to investigate a possibility of use of the new models of pessaries in clinical practice. In future we are planning to 
carry out detailed comparative analysis using different models of currently used pessaries.

\section{Conclusion}

The major challenge of prevention of preterm birth and continuation of the pregnancy puts the task to manage isthmic-cervical insufficiency and recurrent miscarriage.

Application of the new model of obstetrical pessary considerably increases the chances of successful maintenance of pregnancy course to term in women with cervical insufficiency and habitual abortion and reduces negative health outcomes.

\section{Reference}

1. Goya M, Pratcorona L, Merced C, Rodó C, Valle L, et al. (2012) Cervical pessary in pregnant women with a short cervix (PECEP): an open-label randomized controlled trial. Lancet 379: 1800-6.

2. Arabin B, Halbesma JR, Vork F, Hübener M, van Eyck J (2003) Is treatment with vaginal pessaries an option in patients with a sonographically detected short cervix? J Perinat Med 31: 122-33.

3. Kulakov VI, Serov VN, Sidel'nikova VM (2002) Prezhdevremennye rody-taktika vedenija s uchetom srokov gestacii [Premature labor-management tactics in view of gestation]. Zhurnal akusherstva i zhenskih boleznej 2: 13-8.

4. Sidel'nikova VM (2009) Nevynashivanie beremennosti [Miscarriage].

5. Schneiderman M (2014) Patent N142309 Obstetrical pessary Recorded into the state registry of utility models of the Russian Federation.

6. Schneiderman M (2014) A new Russian model of obstetrical pessary Материалы XV Всероссийского научного форума «Мать и дитя», Москва 23 сентября года.

7. Gorshkov AB, Schneiderman MG, Zhukova EE, Biber BL, Valetova NR, Orlova OE, Kosinova TE Patent for the utility model N138859 Urogynecological device Authors:

Recorded into the state registry of utility models of the Russian Federation 28 February 2014

Materials from the XV Russian scientific forum "Mother and Child", Moscow, 23 September 2014.

8. Schneiderman MG (2015) A new Russian model of obstetrical pessary for preventive care and treatment of cervical insufficiency and habitual abortion. Materials from the XVI Russian scientific forum "Mother and Child" 22-25.

9. Schneiderman MG, Tetruashvili NK, Kan NY, Klimenchenkp NI, Kalinina EAet al. (2015) A new Russian model of obstetrical pessary for preventive care and treatment of cervical insufficiency and habitual abortion. Materials from the VIII Regional scientific forum "Mother and Child" 73-74.

10. Schneiderman MG, Gorshkov AV (2016) A new model of gynecological and obstetrical pessary. Mag Gynecol 18: 92-95.

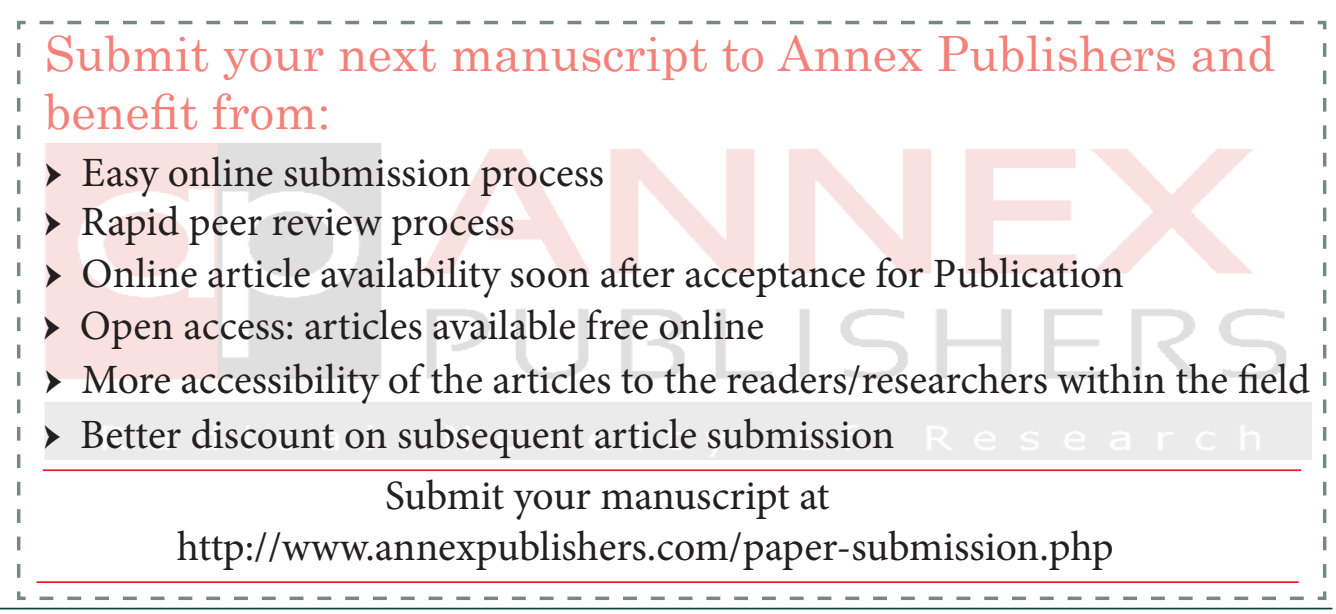

